\title{
New Development in Nanoporous Composites: Novel Functional Materials for Capturing Nitrosamines in Airstreams
}

\author{
Ting Ting Zhuang, ${ }^{1}$ Jia Hui Xu, ${ }^{1}$ Jia Rong Xia, ${ }^{2}$ Yi Cao, ${ }^{1}$ Shi Lu Zhou, ${ }^{2}$ Ying Wang, ${ }^{2}$ \\ Yuan Chun, ${ }^{1}$ and Jian Hua Zhu ${ }^{1}$ \\ ${ }^{1}$ Laboratory of Mesoscopic Chemistry, School of Chemistry and Chemical Engineering, Nanjing University, Nanjing 210093, China \\ ${ }^{2}$ Department of Chemistry, School of Chemistry and Chemical Engineering, Nanjing University, Nanjing 210093, China
}

Received 13 March 2006; Revised 25 July 2006; Accepted 2 August 2006

The latest progresses of the series of research on the trapper of nitrosamines are reported in this paper, involving the attempts to elevate the selective adsorption of zeolites through enhancing adsorbent-adsorbate interaction, in order to prepare the new functional nanoporous materials with high efficiency to eliminate the carcinogenic pollutants in environment and to protect public health. Incorporation of metal oxide such as copper oxide in $\mathrm{NaY}$ accelerated adsorption of volatile nitrosamines and anthracene, and moreover, coating zirconia onto the zeolite could dramatically suppress the release of nitrogen oxides in the decomposition of $N$-nitrosopyrrolidine (NPYR) during temperature-programmed surface reaction (TPSR) process.

Copyright (c) 2006 Ting Ting Zhuang et al. This is an open access article distributed under the Creative Commons Attribution License, which permits unrestricted use, distribution, and reproduction in any medium, provided the original work is properly cited.

\section{INTRODUCTION}

Developing new processes for chemical production and controlling the environment pollution are two main challenges faced by the chemists of the 21st century, and these are also the new applications of nanoporous functional materials. Apart from a number of novel catalysts and adsorbents designed and synthesized for chemical industry, many efforts have been done for the protection of environment that connects the life of people much closer. Among these extensive efforts to be undertaken, one of the new developing areas of study is the application of nanoporous functional materials such as zeolites, because zeolite has excellent thermal and chemical stability along with the unique shape selectivity and sieving effect. These inherent features enable the nanoporous materials to recognize, discriminate, and organize molecules with precisions that can be less than $0.1 \mathrm{~nm}$ [1], and a noteworthy example is the zeolite additive in cigarette to remove carcinogenic agents like nitrosamines because smoking is a global problem causing health hazard [2-5]. Nitrosamines are known to be toxicant chemical not only to cause poisoning some times, but also to induce cancer and tumor in almost all organs of experimental animals [6]. They are important contributors to the total burden of carcinogens resulting from tobacco, especially the tobacco smoke, since the nitrosamines in tobacco products and tobacco smoke can be directly deposited into the blood following inhalation through smoking. Moreover, environmental tobacco smoke is one of the major contaminants of indoor air leading to considerable exposure for the nonsmoker through passive smoking. Thus, removal of carcinogenic compounds from environment is important for environment protection. Zeolites are the potential trapper of nitrosamines owing to their unique function of selective adsorption, and about 50-70\% of nitrosamines in smoke can be eliminated $[2,4]$. In early literature this function of zeolite was attributed to its catalysis, but detailed researches reveal the crucial role played by the selective adsorption of zeolite [7-12]. The extraordinary interaction for the $\mathrm{N}-\mathrm{NO}$ functional group of nitrosamines enables zeolite to capture the carcinogenic compounds in the smoke that contains more than 4000 components; even the zeolite A is able to adsorb the volatile nitrosamines through an especial inserting model of adsorption $[13,14]$, in which the carcinogens adsorb in zeolite by inserting the $\mathrm{N}-\mathrm{NO}$ functional group into the narrow channel.

To meet the requirement of reducing the nitrosamines level in the aeration system of tower where the flow rate of airstreams is very large and the concentration of nitrosamines relatively lower [15], however, new functional nanoporous materials with higher efficiency are sought. These novel 
candidates should have stronger capability to selectively adsorb nitrosamines and, if possible, other carcinogenic compounds in airstreams. Recently our group tried to incorporate copper oxide on $\mathrm{NaY}$ zeolite through impregnation method, and successfully enhanced its ability of trapping volatile nitrosamines, say, about one time higher, in the smoke of Chinese Virginia-type cigarette [16-19]. Nonetheless, suspicions still exist on the modified zeolites concerning whether they can adsorb the bulky polycyclic aromatic hydrocarbons (PAHs), that is, another carcinogens, in airstreams. Besides, further study is required to explore the possibility of replacing copper oxide by other metal oxides for lower cost and higher environmental benignity of the nanoporous functional materials.

In most cases, the degradation of nitrosamines, catalyzed by the modified zeolites or mesoporous silica, releases gaseous nitrogen oxides $\mathrm{NOx}$ due to the rupture of $\mathrm{N}-\mathrm{NO}$ band in the carcinogenic molecule, which, however, is not environmental benign anyway. Therefore, seeking another modifier to replace copper oxide for these porous adsorbents is another aim of the present paper, and the candidate should be able to obviously reduce the release of NOx during the catalytic decomposition of nitrosamines. Based on our foregoing investigation [20, 21], zirconia is chosen because of its weak acidity and weak basicity. Nitrosamines possess both weak acidity and weak basicity, too; therefore establishing a suitable chemical environment in the nanoporous adsorbent should be beneficial to promote the decomposition of the worst carcinogenic compounds. Nonetheless the reason why the zirconia-coated zeolites can reduce the release of NOx in the catalytic degradation of nitrosamines is still not understood, which spurs us to critically examine the property-function relations of zirconia embedded in zeolite, not only for deep understanding of the selective removal of nitrosamines, but also for seeking the new concept for creating novel functional nanoporous materials.

\section{EXPERIMENTAL}

Three volatile nitrosamines, the $N$-nitrosodimethylamine (NDMA), the $N$-nitrosopyrrolidine (NPYR), and the $N$ nitrosohexamethyleneimine (NHMI), were purchased from Sigma and dissolved in dichloromethane with volume ratio of $1: 19$, and stored at $273 \mathrm{~K}$. Anthracene (Ant) was also obtained from Sigma and dissolved in cyclohexane with weight ratio of 0.18 . Zeolite $\mathrm{NaY}$, with $\mathrm{Si} / \mathrm{Al}$ of 2.86 and a surface area of $766 \mathrm{~m}^{2} \cdot \mathrm{g}^{-1}$, was purchased from Wenzhou catalyst factory (China). NaZSM-5 zeolite, with $\mathrm{Si} / \mathrm{Al}$ ratio of 23, was provided by the catalysts factory of Nankai University (China). It possesses the surface area of $354 \mathrm{~m}^{2} \cdot \mathrm{g}^{-1}$ and the mean crystal size of $7 \mu \mathrm{m}$.

Copper was incorporated in the porous support using "drying impregnation": $0.456 \mathrm{~g} \mathrm{Cu}\left(\mathrm{NO}_{3}\right)_{2} \cdot 3 \mathrm{H}_{2} \mathrm{O}$ was dissolved in $40 \mathrm{ml} \mathrm{H}_{2} \mathrm{O}$ and $5 \mathrm{~g} \mathrm{NaY}$ added; the mixture was stirred strongly and heated up to half dryness; then dried at $373 \mathrm{~K}$ overnight; finally the product was ground to
100 mesh and calcined at $773 \mathrm{~K}$ for $6 \mathrm{~h}$ in order to convert $\mathrm{Cu}\left(\mathrm{NO}_{3}\right)_{2}$ to copper oxide. The resulting sample contained $3 \%(\mathrm{w} / \mathrm{w}) \mathrm{CuO}$ and to be denoted as $3 \% \mathrm{CuO} / \mathrm{NaY}$. Other samples were prepared in the same way and the concentration of aqueous solution was controlled to get different loadings of copper cations. Through similar process $\mathrm{ZnO}$ or $\mathrm{Fe}_{2} \mathrm{O}_{3}$ was loaded on zeolites. The purity of carrier gases $\mathrm{N}_{2}$ and $\mathrm{H}_{2}$ was $99.99 \%$, and all agents used were of AR grade. For the preparation of zirconia-modified zeolite, the guest oxide $\mathrm{ZrO}_{2}$ (Toray Ltd., SA $=120 \mathrm{~m}^{2} \cdot \mathrm{g}^{-1}$ ) was first ground along with $\mathrm{NaY}$ zeolite at a given weight ratio, then radiated in a microwave oven $(2450 \mathrm{MHz}, 850 \mathrm{~W})$ for 20 minutes. The resulting materials were characterized by XRD, that carried out on an ARL XTRA diffractometer with $\mathrm{Cu} K \alpha$ radiation, and the XRD peak intensity ratio of $\mathrm{ZrO}_{2}$ (111) to that of $\mathrm{NaY}$ (111) represented the proportion of the residual bulk zirconia in the sample. The static adsorption of $n$-hexane at $303 \mathrm{~K}$ was employed to characterize the pore volume of the nanoporous samples, in which the sample was evacuated at $673 \mathrm{~K}$ for $2 \mathrm{~h}$ then cooled to $303 \mathrm{~K}$ to contact with the adsorbate at the given pressure. XPS measurements on the VG ESCALab MK II instrument were performed using a $1253.6 \mathrm{eV} \mathrm{K} \alpha$ magnesium X-ray source, the energy scale of spectrometer was calibrated by setting the measured C1S binding energy to $284.6 \mathrm{eV}$. The concentration of each element was then calculated from the area of the corresponding peak, calibrated by using the relative sensitivity factor of Wagner.

Instantaneous adsorption of volatile nitrosamines is performed in a stainless steel microreactor whose one end inserts deeply into the injector port of Varian 3380 gas chromatograph (GC), while another end connects with the separation column in the GC. five mg samples, in 20-40 meshes, were filled in the reactor and sealed by glass wool to fix the position where the temperature could be accurately controlled by the injector port of GC. The sample was directly heated to the given temperature, without activation, in the flow of $\mathrm{H}_{2}$ with a rate of $30 \mathrm{ml} \cdot \mathrm{min}^{-1}$, and the nitrosamine solution was pulse injected with amounts of $2 \mu \mathrm{l}$ each time. After being gasified in the injector, the nitrosamines were pushed by the carrier gas with a speed of $25 \mathrm{~cm} \cdot \mathrm{s}^{-1}$ to pass through the zeolite bed layer then to the packed column, and the response at the column outlet was recorded by the GC with thermal conductivity detector. The rejection was repeated for several times over several hours to examine the capability of zeolite to capture the nitrosamines in gas stream. To avoid environment contamination, exhaust gas was treated by acid solution to destroy nitrosamines.

In the experiment of temperature-programmed surface reaction (TPSR), $20 \mathrm{mg}$ sample was activated in $\mathrm{N}_{2}$ at $773 \mathrm{~K}$ for $2 \mathrm{~h}$. NPYR solution was injected in the sample at $423 \mathrm{~K}$ followed by purge of $\mathrm{N}_{2}$ for $0.2 \mathrm{~h}$, then the temperature of the sample was increased from $423 \mathrm{~K}$ to $773 \mathrm{~K}$ at the rate of $8 \mathrm{~K} \cdot \mathrm{min}^{-1}$ and kept at $773 \mathrm{~K}$ for $0.5 \mathrm{~h}$; the cracking products of nitrosamines were detected every $20 \mathrm{~K}$ by spectrophotometric method [5]. 


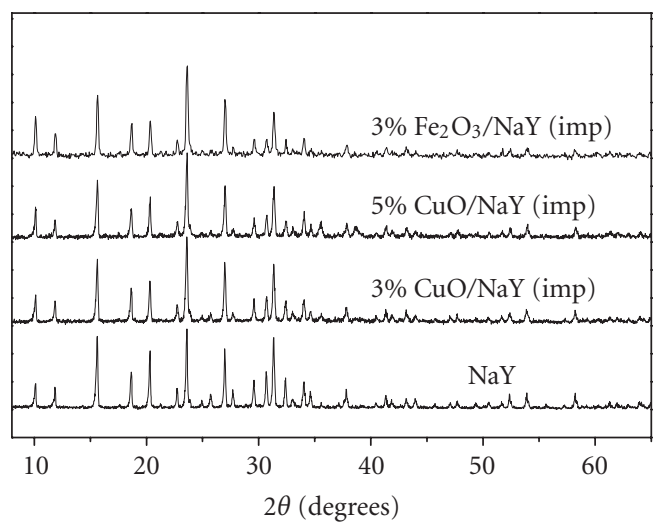

(a)

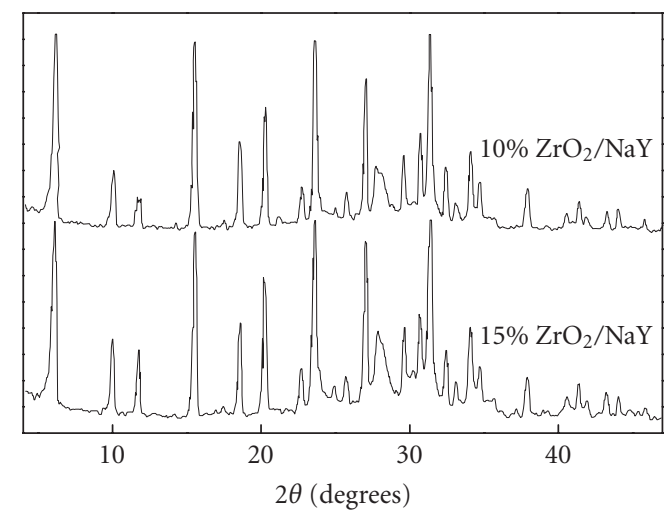

(b)

FIGURE 1: XRD patterns of transitional metal oxide-modified NaY samples.

\section{RESULTS AND DISCUSSION}

\subsection{Characterization of the zeolite modified with metal oxide}

Figure 1(a) depicts the dispersion of metal oxides on zeolite $\mathrm{NaY}$, and all of three samples incorporated copper oxide or ferric oxide show the identical XRD patterns to that of parent zeolite $\mathrm{NaY}$. No extra phase is observed in the case of loading 3 wt. $\%$ of copper oxide or ferric oxide on $\mathrm{NaY}$, and increasing the loading amount of copper oxide to $5 \mathrm{wt}$. $\%$ cannot create the crystal phase of the guest on the patterns of the composite, either. It appears that the impregnation process can well disperse the metal oxide-like copper oxide or ferric oxide in zeolite $\mathrm{NaY}$ provided the loading amount is about 3 wt. $-\%$.

Well-dispersion of zirconia in zeolite $\mathrm{NaY}$ was also observed. Microwave radiation did not damage the pore structure of $\mathrm{NaY}$ zeolite under the experimental conditions we used here $[22,23]$. After the mixture of $\mathrm{NaY}$ and zirconia was microwave-radiated, no characteristic XRD peak of zirconia emerged in the patterns with the $2 \theta$ value of $28.1^{\circ}$, and the composite exhibited the same XRD pat-

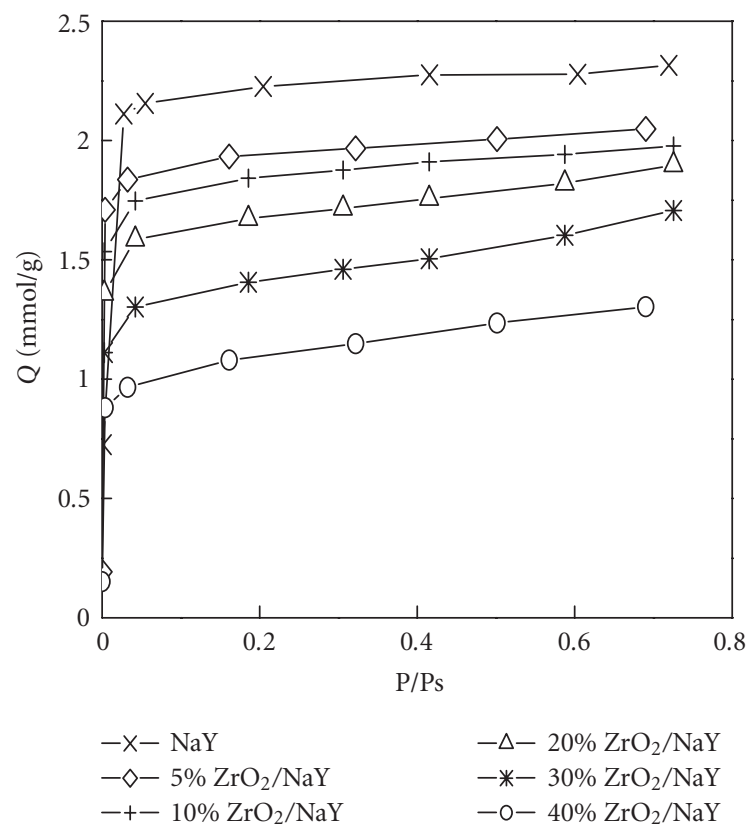

Figure 2: The isotherm of $n$-hexane adsorbed in zirconia-modified zeolite $\mathrm{NaY}$ at $303 \mathrm{~K}$.

TABLE 1: Impact of loading zirconia on the adsorption of $n$-hexane in zeolite $\mathrm{NaY}(\mathrm{P} / \mathrm{Ps}=0.7$, at $303 \mathrm{~K})$.

\begin{tabular}{l|llrrrr}
\hline Loading amount (wt.-\%) & \multicolumn{1}{l}{5} & 5 & 10 & \multicolumn{1}{c}{20} & \multicolumn{1}{c}{30} & 40 \\
Adsorption (mmol/g) & 2.3 & 2.1 & 2.0 & 1.9 & 1.7 & 1.3 \\
Decrease (\%) & - & 8.9 & 13.0 & 17.4 & 26.1 & 43.5 \\
\hline
\end{tabular}

terns as that of zeolite $\mathrm{NaY}$, even the loading amount reached 15 wt.- $\%$ (Figure $1(\mathrm{~b})$ ), since the spontaneous dispersion threshold of zirconia in the zeolite was $15 \mathrm{wt} .-\%$ [21]. However, adsorptive isotherm of $n$-hexane revealed the variation of the pore volume of the resulting composites. As is evident from Figure 2 and Table 1, the pore volume of zeolite $\mathrm{NaY}$ host, represented by the adsorption amount of $n$-hexane at $303 \mathrm{~K}$, is gradually lowered owing to the occupation of the channel of zeolite by the guest oxide. Besides, the isotherm of $20 \% \mathrm{ZrO}_{2} / \mathrm{NaY}$ sample became turnuped as the $\mathrm{P} / \mathrm{Ps}$ exceeded 0.4 , and such trend was observed on the sample of $30 \% \mathrm{ZrO}_{2} / \mathrm{NaY}$ and $40 \% \mathrm{ZrO}_{2} / \mathrm{NaY}$. Nonetheless, the adsorption isotherm of $n$ hexane on $\mathrm{ZrO}_{2} / \mathrm{NaY}$ sample still kept its original Langmuir type as that on zeolite $\mathrm{NaY}$ (Figure 2). This phenomenon demonstrates the existence of the uniform channel in the $\mathrm{ZrO}_{2} / \mathrm{NaY}$ composites, that is, the characteristic of zeolite and very important for selective adsorption or catalysis. In general the reduced pore volume of zeolites goes against their adsorption of nitrosamines [12, 14 ], consequently the sample loaded with the zirconia of more than $20 \mathrm{wt} . \mathrm{\%}$ will not be used for further experiments. 


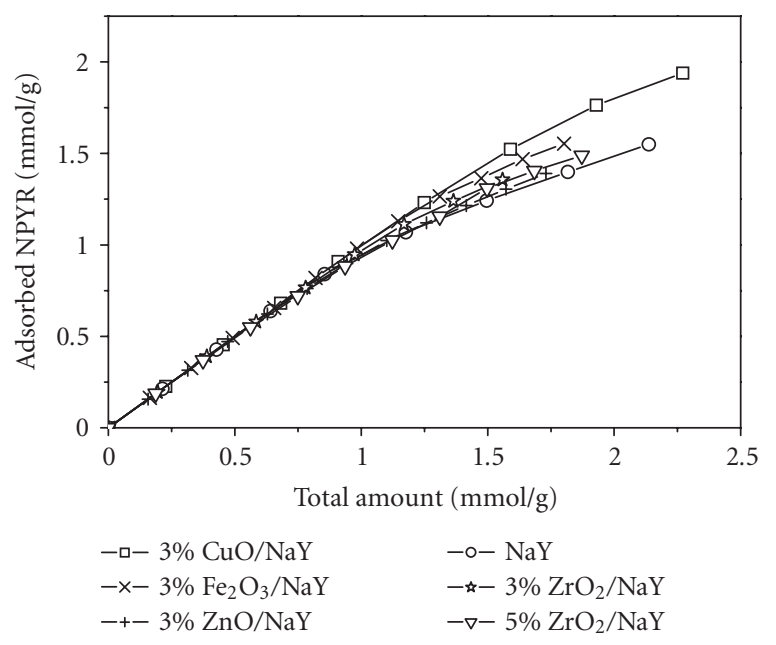

FIgURE 3: Adsorption of NPYR in zeolite $\mathrm{NaY}$ and metal oxidemodified $\mathrm{NaY}$ at $453 \mathrm{~K}$.

\subsection{The promoted adsorption capacity of zeolite for trapping nitrosamines in stream}

Figure 3 illustrates the impact of loading $3 \mathrm{wt} .-\%$ transitional metal oxide on the capacity of zeolite $\mathrm{NaY}$ for instantaneous adsorbing NPYR at $453 \mathrm{~K}$. It should be pointed out that the contact time between the adsorbent and the nitrosamines is very short in these tests, say, less than $0.1 \mathrm{sec}-$ ond, which is similar to that in actual application of zeolites in aeration system. Both copper oxide and ferric oxide show an obvious promotion on zeolite $\mathrm{NaY}$ while a faint effect is found in the modification with zinc oxide. When the accumulated amount of NPYR reached $1.00 \mathrm{mmol} \cdot \mathrm{g}^{-1}$, $\mathrm{CuO} / \mathrm{NaY}$ or $\mathrm{Fe}_{2} \mathrm{O}_{3} / \mathrm{NaY}$ could adsorb $99.2 \%$ of the carcinogenic compound while $\mathrm{ZnO} / \mathrm{NaY}$ or $\mathrm{NaY}$ adsorbed $93.8 \%$. As the accumulated amount of NPYR increased to $1.70 \mathrm{mmol} \cdot \mathrm{g}^{-1}, \mathrm{ZnO} / \mathrm{NaY}$ exhibited a little larger adsorption capacity $(81.0 \%)$ than the parent zeolite $(78.5 \%)$. Promoted adsorption of nitrosamines in stream by zeolite is also observed on the samples of $3 \% \mathrm{ZrO}_{2} / \mathrm{NaY}$ and $5 \% \mathrm{ZrO}_{2} / \mathrm{NaY}$, and they exhibit an enhanced adsorptive capacity slightly higher than both parent zeolite and zinc-modified $\mathrm{NaY}$ as demonstrated in Figure 3. Nitrosamines adsorbed in zeolite through the manner of inserting the $\mathrm{N}-\mathrm{NO}$ group into the channel $[9,10,12]$, which is accelerated by the strong interaction with the metal ions in the zeolite. Among the metal oxides used here, $\mathrm{CuO}$ appears to be the best one, however ferric oxide-modified sample possesses an excellent promotion function on the adsorptive ability of zeolite $\mathrm{NaY}$, much close to that of copper-modified sample (Figure 3), which implies the possibility of replacing copper modifier by ferric oxide to promote the adsorptive capability of zeolite.

Figure 4 shows the promotion of $\mathrm{CuO}$ on the adsorption of NPYR in different zeolites. As the accumulated amount of NPYR rose from 0.5 to $1.5 \mathrm{mmol} \cdot \mathrm{g}^{-1}, \mathrm{CuO} / \mathrm{NaY}$ ad-

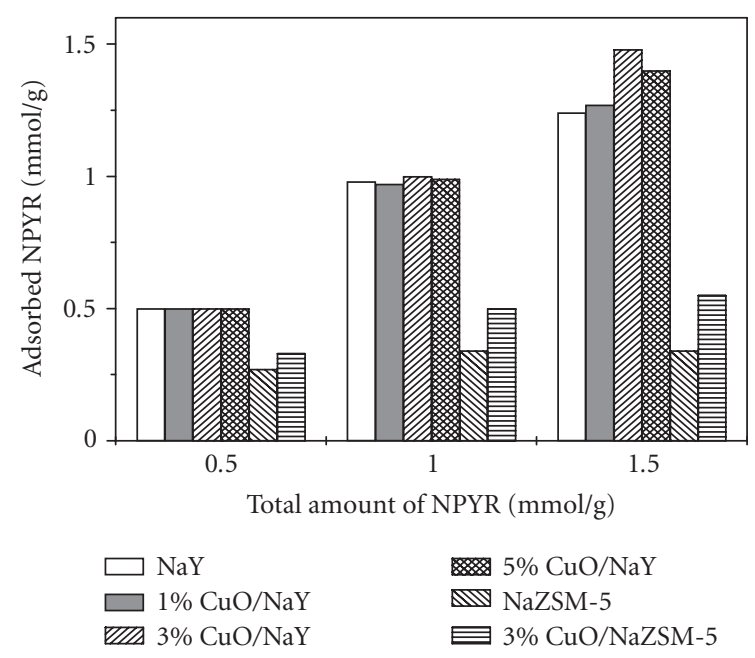

FIgURE 4: Amount of NPYR adsorbed on zeolites Y and ZSM-5 before and after loading copper oxide at $453 \mathrm{~K}$.

sorbed more NPYR than NaY $\left(1.24 \mathrm{mmol} \cdot \mathrm{g}^{-1}\right)$, and the highest capacity was observed on $3 \% \mathrm{CuO} / \mathrm{NaY}$ sample $\left(1.48 \mathrm{mmol} \cdot \mathrm{g}^{-1}\right)$. Promotion of $\mathrm{CuO}$ became more obvious on NaZSM- 5 zeolite, and the $3 \% \mathrm{CuO} / \mathrm{NaZSM}-5$ adsorbed more NPYR $\left(0.33 \mathrm{mmol} \cdot \mathrm{g}^{-1}\right)$ than the parent zeolite $\left(0.27 \mathrm{mmol} \cdot \mathrm{g}^{-1}\right)$ even at the low accumulated amount of NPYR $\left(0.5 \mathrm{mmol} \cdot \mathrm{g}^{-1}\right)$. This difference became larger when the accumulated amount of NPYR reached $1.5 \mathrm{mmol} \cdot \mathrm{g}^{-1}$ : the former adsorbed $0.55 \mathrm{mmol} \cdot \mathrm{g}^{-1}$ while the latter adsorbed $0.34 \mathrm{mmol} \cdot \mathrm{g}^{-1}$. The adsorptive capability of NaZSM5 is elevated about $60 \%$.

Figure 5 depicts the impact of the molecular size on the adsorption of nitrosamines in the copper modification $\mathrm{NaY}$ zeolite. NDMA, NPYR, and NHMI have the molecular diameter of $0.45,0.56$, and $0.59 \mathrm{~nm}$, respectively $[12,24]$, so that the adsorbed amount of three nitrosamines is diverse. For $\mathrm{NaY}$ when the accumulated amount of nitrosamines arrived $1.25 \mathrm{mmol} \cdot \mathrm{g}^{-1}, 70.5 \%$ of NHMI, $94.6 \%$ of NDMA, or NPYR could be adsorbed. In case $2.40 \mathrm{mmol} \cdot \mathrm{g}^{-1}$ of nitrosamines passed through the adsorbents, about $85.7 \%$ of NDMA and $72.0 \%$ of NPYR were adsorbed. No doubt the NDMA with the smallest molecular volume can be adsorbed in zeolite much more easily due to its fast diffusion inside the channel of adsorbent [7]. Same tendency was found on $3 \% \mathrm{CuO} / \mathrm{NaY}$. When the accumulated amount reached $1.25 \mathrm{mmol} \cdot \mathrm{g}^{-1}, 64.1 \%$ of NHMI, $97.9 \%$ of NDMA, or NPYR could be adsorbed; while the amount rose to $2.40 \mathrm{mmol} \cdot \mathrm{g}^{-1}$, $95.1 \%$ of NDMA and $82.9 \%$ of NPYR were adsorbed. It is conclusive that the difference between the adsorption of three volatile nitrosamines is magnified on the coppermodified zeolite: more NDMA or NPYR but less NHMI adsorbed on the sample of $3 \% \mathrm{CuO} / \mathrm{NaY}$. That is to say, incorporation of copper oxide delicately modifies the channel of zeolite and made the shape selectivity increased which may be beneficial for the separation in environment protection. 


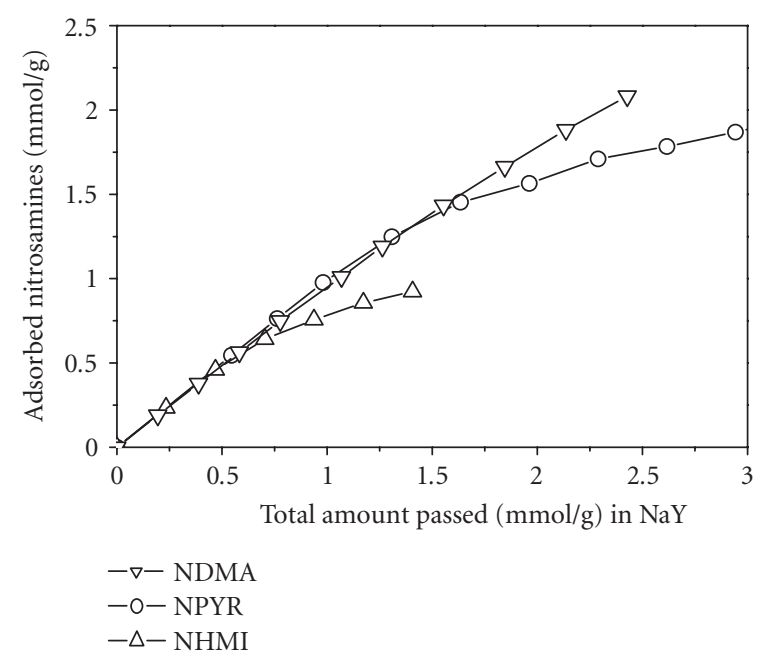

(a)

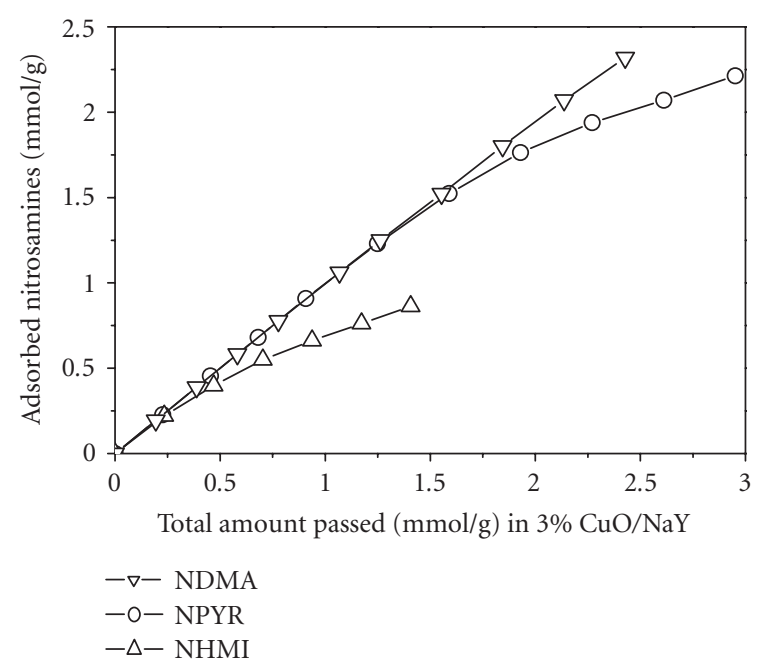

(b)

Figure 5: Different nitrosamines adsorbed on (a) $\mathrm{NaY}$ and (b) $3 \% \mathrm{CuO} / \mathrm{NaY}$ at $453 \mathrm{~K}$.

Figure 6 shows the adsorption of anthracene (Ant), one of polycyclic aromatic hydrocarbons that exists widely in environment such as smoke [25], on zeolite NaY. In case that the accumulated amount of Ant was $30.0 \mathrm{mg} \cdot \mathrm{g}^{-1}, 70.4 \%$ of the adsorbate could be trapped by $\mathrm{NaY}$. For $3 \% \mathrm{CuO} / \mathrm{NaY}$, the corresponding value was $94 \%$, one third higher than that of the parent zeolite. As is evidenced from Figure 6, the sample of $3 \% \mathrm{CuO} / \mathrm{NaY}$ can capture more anthracene molecules than $\mathrm{NaY}$ zeolite in the instantaneous adsorption in which the contact time is less than 0.1 second. This result replies a new application of the copper-modified nanoporous adsorbent in protection of environment, and this functional material may be used to trap the polycyclic aromatic hydrocarbons (PAH) in aeration system of tower. It is the first time to find the promotion of $\mathrm{CuO}$ modification on the instantaneous adsorption of both nitrosamines and PAH in zeolite

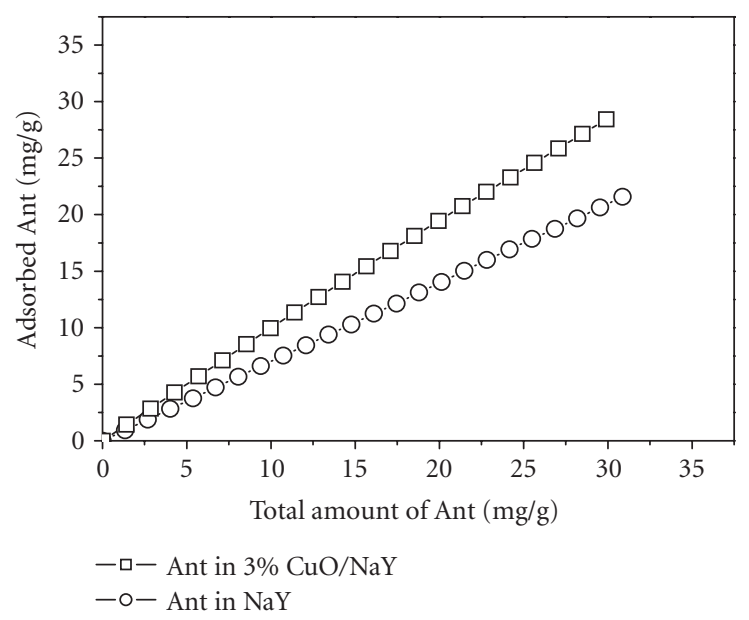

Figure 6: Anthracene (Ant) adsorbed on $\mathrm{NaY}$ and $3 \% \mathrm{CuO} / \mathrm{NaY}$ at $503 \mathrm{~K}$.

$\mathrm{NaY}$, but the mechanisms of the promotion may be different. Copper oxide attracts the $\mathrm{N}-\mathrm{NO}$ group, through the interaction similar to that with NOx [26], to accelerate adsorption of nitrosamines in $\mathrm{NaY}$. Anthracene consists of only $\mathrm{C}$ and $\mathrm{H}$ without $\mathrm{N}$ and $\mathrm{O}$ as well as $\mathrm{N}-\mathrm{NO}$ group, so the copper nanoparticles embedded in $\mathrm{NaY}$ cannot induce it into the channel as that happens in the case of nitrosamines. Decoration of channel of the adsorbent may result in this promotion, since the copper oxide dispersed into the channel of $\mathrm{NaY}$ should reduce the actual pore size, even a little. Anthracene has a molecular size of $0.49 \mathrm{~nm}$, smaller than the pore size of $\mathrm{NaY}(0.76 \mathrm{~nm})$, so the delicately reducing of the pore size and/or the curvature of channel in the adsorbent will be helpful for anthracene because the confinement of channel is elevated and thus forms a stronger adsorbateadsorbent interaction with the adsorbate. Judged on these results, it seems feasible to promote adsorption of both nitrosamines and PAH in airstreams by nanoporous materials like zeolite, through tailoring the pore structure and surface state by coating metal oxide on the porous host.

\subsection{Suppressing the release of nitric oxygen in decomposition of nitrosamines on zeolite $\mathrm{NaY}$}

Figure 7 depicts the degradation of NPYR on zeolite $\mathrm{NaY}$ in the temperature-programmed surface reaction (TPSR) process. NPYR is a volatile nitrosamines consisting of fivemembered ring and its degradation starts from the rupture of $\mathrm{N}-\mathrm{NO}$ bond to release nitric oxygen product $[27,28]$. Consequently, the detected nitric oxide and other nitrogen oxides, that result from the further reactions of the primary nitric oxide, represent the amount of nitrosamines to be degrated $[5,8]$. The NPYR adsorbed in $\mathrm{ZrO}_{2} / \mathrm{NaY}$ began to degrade and liberate $\mathrm{NOx}$ at $473 \mathrm{~K}$ when nitrogen was used as the carrier gas, giving rise to a maximum concentration of NOx near $593 \mathrm{~K}$ on the sample of $5 \% \mathrm{ZrO}_{2} / \mathrm{NaY}$ 


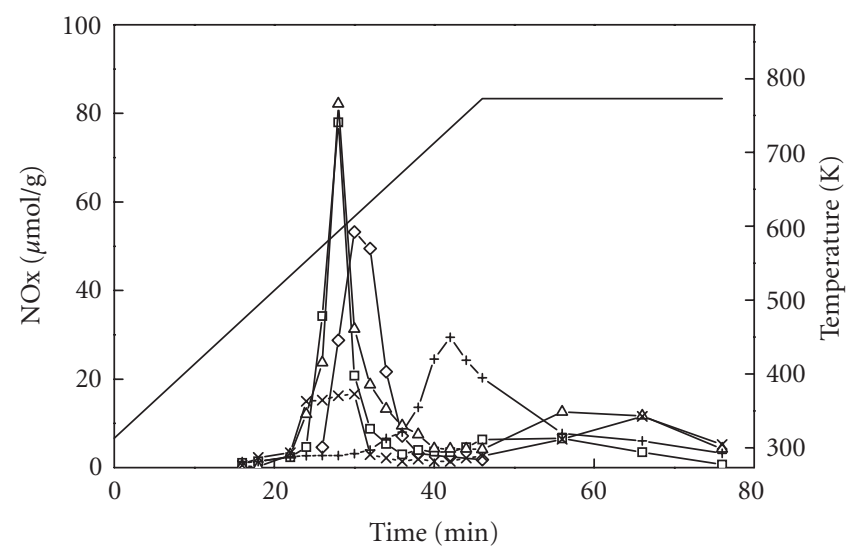

$$
\begin{array}{ll}
-\diamond-\mathrm{NaY} & -\times-20 \% \mathrm{ZrO}_{2} / \mathrm{NaY} \\
-\square-5 \% \mathrm{ZrO}_{2} / \mathrm{NaY} & -+-\mathrm{ZrO}_{2} \\
-\triangle-10 \% \mathrm{ZrO}_{2} / \mathrm{NaY} & - \text { Temperature }
\end{array}
$$

Figure 7: Impact of loading zirconia in zeolite NaY on the decomposition of NPYR.

and $10 \% \mathrm{ZrO}_{2} / \mathrm{NaY}$ with the amount of 78 and $82 \mu \mathrm{mol} \cdot \mathrm{g}^{-1}$, respectively. When the reaction temperature was hold at $773 \mathrm{~K}$ for $0.5 \mathrm{~h}$, another unconspicuous desorption of nitrogen oxides appeared on $5 \% \mathrm{ZrO}_{2} / \mathrm{NaY}$ with a relative low concentration of about $6.6 \mu \mathrm{mol} \cdot \mathrm{g}^{-1}$. This phenomenon became obvious in the sample of $10 \% \mathrm{ZrO}_{2} / \mathrm{NaY}$ and the corresponding value increased to $11.8 \mu \mathrm{mol} \cdot \mathrm{g}^{-1}$. As a comparison, the maximum value of $53 \mu \mathrm{mol} \cdot \mathrm{g}^{-1}$ emerged on parent zeolite $\mathrm{NaY}$ at $613 \mathrm{~K}$, and no further desorption of NOx was detected during which the sample was hold at $773 \mathrm{~K}$ (Figure 7). The unsupported zirconia itself could adsorb a considerable amount of nitrosamines and most of them seemed to be decomposed at around $733 \mathrm{~K}$, giving rise to a maximum concentration of $29 \mu \mathrm{mol} \cdot \mathrm{g}^{-1}$. These nitrogen oxides continuously desorbed when the sample was hold at $773 \mathrm{~K}$, similar to that observed on those $\mathrm{ZrO}_{2} / \mathrm{NaY}$ composites. On the basis of these results, it is very likely that desorption of NOx from the zirconia-modified zeolite $\mathrm{NaY}$ at $773 \mathrm{~K}$ in the TPSR process of NPYR originates from the inherent feature of zirconia. The unsupported zirconia is a porous material with a pore volume of $0.23 \mathrm{ml} \cdot \mathrm{g}^{-1}$ and an average pore size of $6.66 \mathrm{~nm}$ [29]. Under the test conditions used here, the detected total amount of NOx in the decomposition of NPYR over zirconia $\left(0.164 \mathrm{mmol} \cdot \mathrm{g}^{-1}\right)$ is smaller than that over zeolite $\mathrm{NaY}\left(0.179 \mathrm{mmol} \cdot \mathrm{g}^{-1}\right)$. However, the surface area of zirconia $\left(120 \mathrm{~m}^{2} \cdot \mathrm{g}^{-1}\right)$ is one sixth of that of $\mathrm{NaY}\left(766 \mathrm{~m}^{2} \cdot \mathrm{g}^{-1}\right)$, so that the oxide probably possesses a comparable capability to $\mathrm{NaY}$ for trapping the volatile nitrosamine if judged on the efficiency per square meter surface area of the sample. Thus, coating zirconia on zeolite $\mathrm{NaY}$ through microwaveradiation considerably enhanced the efficiency for catalytic degradation of NPYR, and more NPYR were degraded at lower temperature than that on the parent zeolite. Moreover, desorption of NOx at high temperature in TPSR process appeared on these nanoporous composites as the characteristic

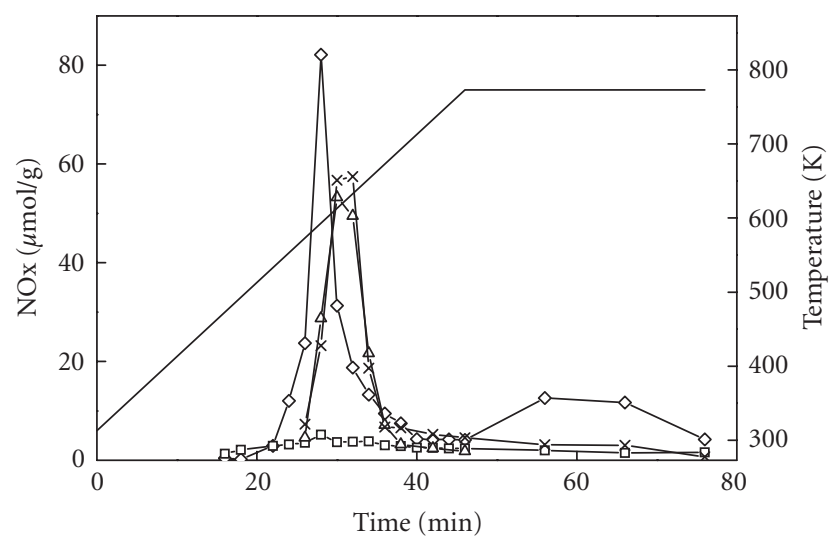

$$
\begin{array}{ll}
-\diamond-10 \% \mathrm{ZrO}_{2} / \mathrm{NaY} \text { in } \mathrm{N}_{2} & -\times-\mathrm{NaY} \text { in air } \\
-\square-10 \% \mathrm{ZrO}_{2} / \mathrm{NaY} \text { in air } & - \text { Temperature } \\
-\triangle-\mathrm{NaY} \text { in } \mathrm{N}_{2} &
\end{array}
$$

FIGURE 8: TPSR of NPYR over zeolite NaY in different carrier gases.

of zirconia. Incorporation of more zirconia in $\mathrm{NaY}$ did not cause further promotion on the catalytic activity of the composite, the detected amount of NOx from the sample of $20 \% \mathrm{ZrO}_{2} / \mathrm{NaY}$ dramatically declined, as demonstrated in Figure 7, at the same time the desorption of NOx at $773 \mathrm{~K}$ was still obvious.

When the carrier gas in TPSR process was changed from nitrogen to air, however, the maximum concentration of NOx released from the sample of $10 \% \mathrm{ZrO}_{2} / \mathrm{NaY}$ was abruptly decreased to below $10 \mu \mathrm{mol} / \mathrm{g}$ under the same conditions (Figure 8). Similar phenomenon was also observed on $5 \% \mathrm{ZrO}_{2} / \mathrm{NaY}$ sample, and these results were confirmed by several repeated experiments. In contrary, only slightly variation was found on the desorption of NOx on NaY zeolite alone, and the concentration of NOx at $633 \mathrm{~K}$ increased from 49.4 to $54.5 \mu \mathrm{mol} \cdot \mathrm{g}^{-1}$ instead, as demonstrated in Figure 8. One may argue that these differences result from the different amounts of NPYR adsorbed on $10 \% \mathrm{ZrO}_{2} / \mathrm{NaY}$ in the different carrier gases, this argument however, is not justified by experiments. Two samples adsorbed NPYR in nitrogen or air prior to the TG-DTA tests, and the similar weight loss (about $8 \%$ ) emerged accompanied by the same exothermal peak of NPYR decomposition that appeared around $473 \mathrm{~K}$ and continued to $873 \mathrm{~K}$ [21], indicating the similar amount of NPYR adsorbed on $\mathrm{ZrO}_{2} / \mathrm{NaY}$ regardless of the kind of carrier gas. To check if the most of adsorbed NPYR escaped from the nanoporous material, the nitrosamine content of the exhaust gas was analyzed. However, only less than $1 \%$ of the adsorbed NPYR was found to desorb from $10 \% \mathrm{ZrO}_{2} / \mathrm{NaY}$ sample during the TPSR process, which confirms that most of the nitrosamines are degraded. This is rationalized by proposing that the products distribution of NPYR degradation is changed in the sample of $10 \% \mathrm{ZrO}_{2} / \mathrm{NaY}$ when the carrier gas becomes air. That is to say, the release of nitrogen oxides is suppressed though the reason is not known yet. 
TABLE 2: XPS analysis of $10 \% \mathrm{ZrO}_{2} / \mathrm{NaY}$ sample.

\begin{tabular}{l|ccrr}
\hline Sample & \multicolumn{2}{|c}{ Before activation } & \multicolumn{2}{c}{ After activation in nitrogen } \\
\hline & Atom \% & Binding energy $(\mathrm{eV})$ & 63.0 & Binding energy $(\mathrm{eV})$ \\
\hline O1s & 66.74 & 531.61 & 3.66 & 531.72 \\
Zr3d & 3.20 & 181.65 & 8.68 & 181.54 \\
Na1s & 7.65 & 1072.15 & 18.68 & 1072.15 \\
Si2p & 16.80 & 102.35 & 5.97 & 102.45 \\
Al2p & 5.59 & 73.95 & 74.25 \\
\hline
\end{tabular}

Figure 9 shows the degradation of NPYR on the unsupported zirconia in different carrier gases. Unlike the sample activated and tested in nitrogen on which a lot of nitrogen oxides formed as aforementioned, only a few the gaseous NOx products were detected on the bare oxide when the sample was activated and tested in air, and the total amount of NOx lowered to $0.009 \mathrm{mmol} \cdot \mathrm{g}^{-1}$, about $5 \%$ of that on the former $\left(0.164 \mathrm{mmol} \cdot \mathrm{g}^{-1}\right)$. If the zirconia was directly used in the TPSR test in air without activation, the analyzed amount of nitrogen oxides $\left(0.133 \mathrm{mmol} \cdot \mathrm{g}^{-1}\right)$ was still smaller than that in nitrogen $\left(0.164 \mathrm{mmol} \cdot \mathrm{g}^{-1}\right)$, however dramatically higher than that activated in air $\left(0.009 \mathrm{mmol} \cdot \mathrm{g}^{-1}\right)$. Accordingly, activation of zirconia in nitrogen seems to elevate its ability to catalyze the formation of nitrogen oxides in decomposition of NPYR. Table 2 lists the XPS analysis results of the zirconia-modified zeolite $\mathrm{NaY}$ before and after activation in nitrogen, and both samples possess the same value of binding energy within the experimental error. This excludes the possibility that activation changes the electrovalent state of zirconium in the composite. Although the surface composition of the sample is slightly changed, say, the concentration of sodium cation increases from $7.65 \%$ to $8.68 \%$, which cannot be used to account for the different catalytic properties of the composite activated in different carrier gases.

Figure 10 illustrates the XRD patterns of bare zirconia activated in air or nitrogen. Two crystal phases monoclinic baddeleyite and tetragonal form exist in the zirconia, and the former has intensity weaker than the latter. The peaks at $2 \theta$ of $30.2^{\circ}, 50.2^{\circ}$, and $60.2^{\circ}$ in the XRD patterns are the characteristic of tetragonal form [30]. After the sample was activated at $773 \mathrm{~K}$ in air, the XRD peak of monoclinic baddeleyite with $2 \theta$ value of $28.3^{\circ}$ [29] became stronger but the tetragonal form was still the main phase. By contrary, activation at $773 \mathrm{~K}$ in nitrogen made the monoclinic baddeleyite to be the primary phase while the peak with $2 \theta$ value of $31.3^{\circ}$ grew dramatically along with that of $28.3^{\circ}$. Drawing on these results, the impact of carrier gas in activation is further proposed. Tetragonal crystal in zirconia is metastable phase $[29,31]$, and activation in nitrogen seems to promote its conversion. Nonetheless, the available data do not allow a discussion of the possible mechanism involved, and further study is thus required to explore the relationship between the phase conversion extent of zirconia and the suppression of nitrogen oxides in TPSR test.

Although the reason why the zirconia-modified zeolite $\mathrm{NaY}$ can strangely suppress the release of NOx during the decomposition of nitrosamines is still enigmatic; discovery

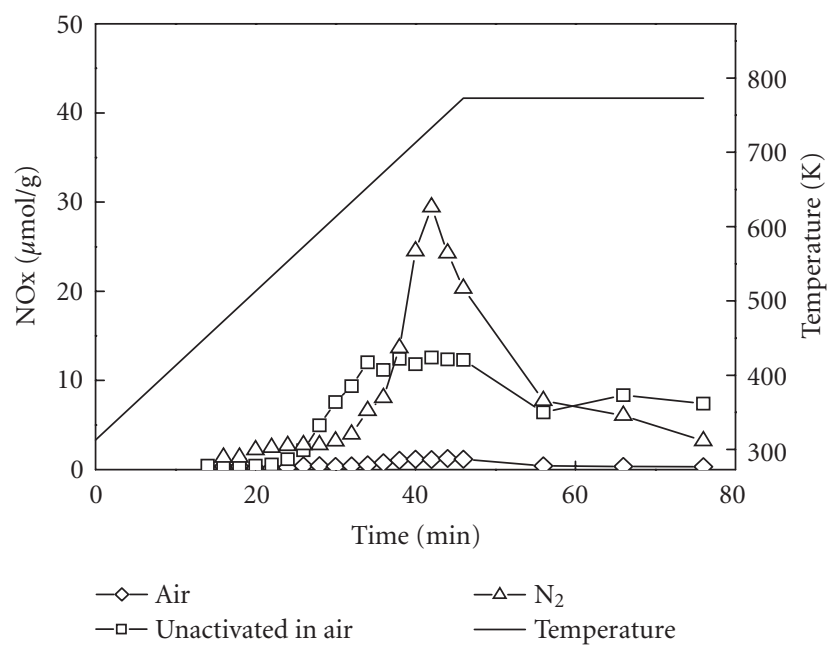

FIGURE 9: Decomposition of NPYR on the unsupported zirconia in different carrier gases.

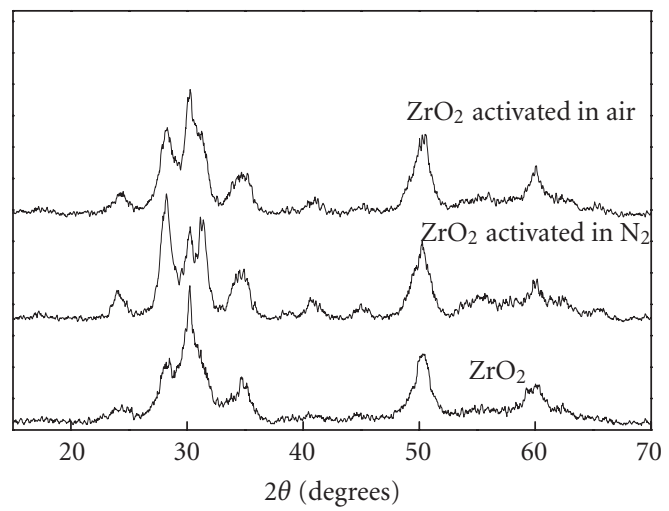

FIGURE 10: XRD patterns of zirconia activated in different atmospheres.

of this unwonted feature of the nanoporous adsorbent gives a clue for design and synthesis of novel functional materials that can act as killer traps for the carcinogenic pollutants in environment, for which choosing suitable guest components and incorporating them inside the pore of nanoporous host will be crucial. 


\section{CONCLUSION}

Incorporation of transitional metal oxide such as copper oxide in zeolite can efficiently elevate the capability of the host to selectivly trap the volatile nitrosamines in airstreams, opening the new application of the nanoporous materials into the aeration system of tower.

Ferric oxide-modified zeolite NaY exhibits a high ability of adsorbing volatile nitrosamines in stream, too, proving the possibility to replace copper oxide for modification of zeolites.

Coating zirconia on $\mathrm{NaY}$ through microwave-radiation can enhance the capability of the zeolite to capture nitrosamines in stream, too, and more importantly it dramatically suppress the release of nitrogen oxides when the decomposition of nitrosamine is performed in air, which may relate with the crystal phase of the guest but further investigation is needed.

\section{ACKNOWLEDGMENTS}

NSF of China (20273031 and 20373024), Ningbo Cigarette Factory, and Analysis Center of Nanjing University financially supported this work.

\section{REFERENCES}

[1] M. E. Davis and R. F. Lobo, "Zeolite and molecular sieve synthesis," Chemistry of Materials, vol. 4, no. 4, pp. 756-768, 1992.

[2] W. M. Meier and K. Siegmann, "Significant reduction of carcinogenic compounds in tobacco smoke by the use of zeolite catalysts," Microporous and Mesoporous Materials, vol. 33, no. 1-3, pp. 307-310, 1999.

[3] Y. Wang, B. Shen, J. H. Zhu, L. Ji, L. L. Ma, and Q. H. Xu, "Investigation on the selective removing $N$-nitrosamines from the smoke of cigarette," Chinese. Environment. Chemistry., vol. 19, pp. 280-286, 2000.

[4] Y. Xu, Y. Wang, J. H. Zhu, L. L. Ma, and L. Liu, "Application of zeolite in the health science: novel additive for cigarette o remove," Studies in Surface Science and Catalysis, vol. 142, pp. 1489-1496, 2002.

[5] Y. Xu, J. H. Zhu, L. L. Ma, A. Ji, Y. L. Wei, and X. Y. Shang, "Removing nitrosamines from mainstream smoke of cigarettes by zeolites," Microporous and Mesoporous Materials, vol. 60, no. 1-3, pp. 125-138, 2003.

[6] S. S. Hecht, "DNA adduct formation from tobacco-specific $N$-nitrosamines," Mutation Research/Fundamental and Molecular Mechanisms of Mutagenesis, vol. 424, no. 1-2, pp. 127-142, 1999.

[7] J. H. Zhu, D. Yan, J. R. Xia, L. L. Ma, and B. Shen, "Attempt to adsorb $\mathrm{N}$-nitrosamines in solution by use of zeolites," Chemosphere, vol. 44, no. 5, pp. 949-956, 2001.

[8] J. H. Zhu, S. L. Zhou, Y. Xu, Y. Cao, and Y.-L. Wei, “Ordered mesoporous materials. Novel catalyst for degradation of $N^{\prime}$ nitrosonornicotine," Chemistry Letters, vol. 32, no. 4, pp. 338 339, 2003.

[9] C. F. Zhou, Z. Y. Yun, Y. Xu, Y. Wang, J. Chen, and J. H. $\mathrm{Zhu}$, "Adsorption and room temperature degradation of $\mathrm{N}$ nitrosodiphenylamine on zeolites," New Journal of Chemistry, vol. 28, no. 7, pp. 807-814, 2004.
[10] Z.-Y. Yun, Y. Xu, J. H. Xu, et al., "In situ FTIR investigation on the adsorption of nitrosamines in zeolites," Microporous and Mesoporous Materials, vol. 72, no. 1-3, pp. 127-135, 2004.

[11] C. F. Zhou and J. H. Zhu, "Adsorption of nitrosamines in acidic solution by zeolites," Chemosphere, vol. 58, no. 1, pp. 109-114, 2005.

[12] C. F. Zhou, Y. Cao, T. T. Zhuang, et al., "Investigation on the adsorption of nitrosamines in zeolites," Studies in Surface Science and Catalysis, vol. 158, pp. 1003-1011, 2005.

[13] J. H. Zhu, B. Shen, Y. Wang, and D. Yan, "Strong selective adsorption of $\mathrm{N}$-nitrosamines on zeolites," Chinese Science Bulletin, vol. 46, pp. 705-707, 2001.

[14] Y. Xu, Z. Y. Yun, C. F. Zhou, S. L. Zhou, J. H. Xu, and J. H. Zhu, "Adsorption of bulky nitrosamines on zeolite with small pore size," Studies in Surface Science and Catalysis, vol. 154, pp. 1858-1865, 2004.

[15] K.-S. Liu, L. E. Alevantis, and F. J. Offermann, "A survey of environmental tobacco smoke controls in California office building," Indoor Air, vol. 11, pp. 25-34, 2001.

[16] Y. Xu, Z.-Y. Yun, J. H. Zhu, et al., "Trapping volatile nitrosamines with copper incorporated zeolites," Chemical Communications, no. 15, pp. 1894-1895, 2003.

[17] Y. Xu, H.-D. Liu, J. H. Zhu, et al., "Removal of volatile nitrosamines with copper modified zeolites," New Journal of Chemistry, vol. 28, no. 2, pp. 244-252, 2004.

[18] H. D. Liu, S. L. Zhou, Y. Wang, Y. Xu, Y. Cao, and J. H. Zhu, "CuO modified NaY zeolite: efficient catalyst for degrading nitrosamines," Studies in Surface Science and Catalysis, vol. 154, pp. 2527-2535, 2004.

[19] L. L. Ma, B. Shen, J. H. Zhu, J. R. Xia, and Q. H. Xu, "Modifying NaY zeolite with metal oxide by microwave irradiation: Influence on the adsorption and decomposition of $\mathrm{N}$ nitrosamines," Chinese Chemical Letters, vol. 11, pp. 649-652, 2000.

[20] J. H. Zhu, J. R. Xia, Y. Wang, G. Xie, J. Xue, and Y. Chun, "ZrO2/NaY: new composite for removal of $N$-nitrosamines pollution," Studies in Surface Science and Catalysis, vol. 135, p. 320, 2001, (30-P-08).

[21] J. R. Xia, J. H. Zhu, Y. Chun, Y. Wang, and R. K. Jia, "Preparing $\mathrm{ZrO} 2 / \mathrm{NaY}$ zeolite-based materials for catalytic degradation of $\mathrm{N}$-nitrosamines by use of microwave irradiation," Acta Chimica Sinica, vol. 59, no. 8, pp. 1196-1200, 2001.

[22] Y. Wang, J. H. Zhu, J. M. Cao, Y. Chun, and Q. H. Xu, "Basic catalytic behavior of $\mathrm{MgO}$ directly dispersed on zeolites by microwave irradiation," Microporous and Mesoporous Materials, vol. 26, no. 1-3, pp. 175-184, 1998.

[23] L. L. Ma, B. Shen, J. H. Zhu, J. R. Xia, and Q. H. Xu, "Modifying $\mathrm{NaY}$ zeolite with metal oxide by microwave irradiation: influence on the adsorption and decomposition of $\mathrm{N}$ nitrosamines," Chinese Chemical Letters, vol. 11, no. 7, pp. 649-652, 2000.

[24] Y. Wang, S. L. Zhou, J. R. Xia, J. Xue, J. H. Xu, and J. H. Zhu, "Trapping and degradation of volatile nitrosamines on cyclodextrin and zeolites," Microporous and Mesoporous Materials, vol. 75, no. 3, pp. 247-254, 2004.

[25] R. R. Baker, "Smoke chemistry," in Tobacco Production, Chemistry and Technology, D. L. Davis and M. T. Nielsen, Eds., pp. 419-426, Blackwell Science, London, UK, 1999.

[26] J. Szanyi and M. T. Paffett, "The adsorption of NO and reaction of $\mathrm{NO}$ with $\mathrm{O}_{2}$ on $\mathrm{H}-, \mathrm{NaH}-, \mathrm{CuH}-$, and $\mathrm{Cu}-\mathrm{ZSM}-5$ : an in Situ FTIR investigation," Journal of Catalysis, vol. 164, no. 1, pp. 232-245, 1996. 
[27] J.-P. Cheng, M. Xian, K. Wang, X. Zhu, Z. Yin, and P. G. Wang, "Heterolytic and homolytic Y-NO bond energy scales of nitroso-containing compounds: chemical origin of NO release and NO capture," Journal of the American Chemical Society, vol. 120, no. 39, pp. 10266-10267, 1998.

[28] K. Hiramoto, Y. Ryuno, and K. Kikugawa, "Decomposition of $\mathrm{N}$-nitrosamines, and concomitant release of nitric oxide by Fenton reagent under physiological conditions," Mutation Research/Genetic Toxicology and Environmental Mutagenesis, vol. 520, no. 1, pp. 103-111, 2002.

[29] Y. Wang, W. Y. Huang, Y. Chun, J. R. Xia, and J. H. Zhu, "Dispersion of potassium nitrate and the resulting strong basicity on zirconia," Chemistry of Materials, vol. 13, no. 2, pp. 670677, 2001.

[30] JCPDS file number 17-0932.

[31] P. Duwez, F. Odell, and F. H. Brown Jr., "Stabilization of zirconia with calcia and magnesia," Journal of the American Ceramic Society, vol. 35, no. 5, pp. 107-113, 1952. 

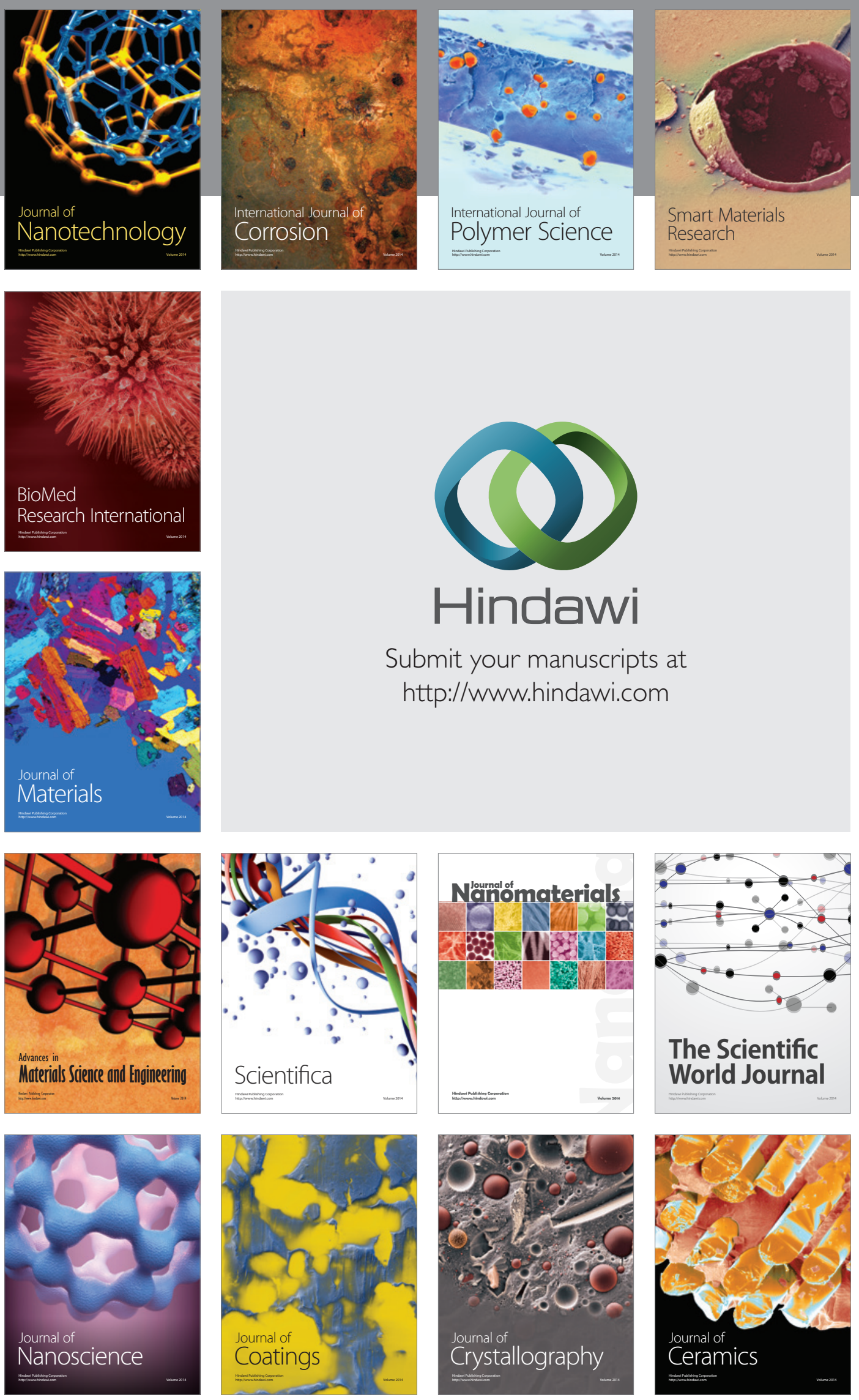

The Scientific World Journal

Submit your manuscripts at

http://www.hindawi.com

\section{World Journal}

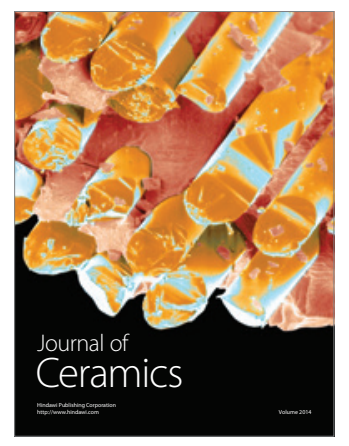

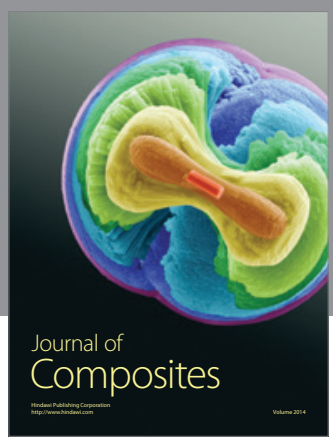
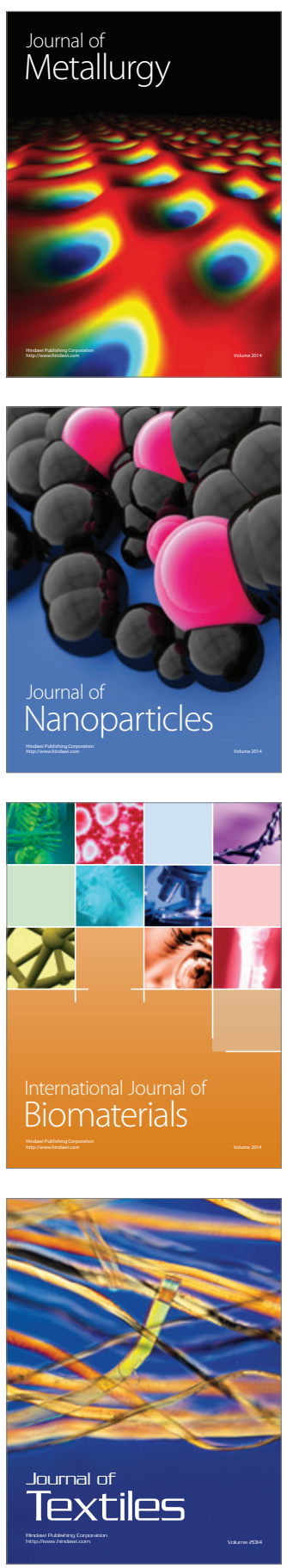